\title{
Megaphones hiding in trees: civic instruction via mediated soundscapes in places of natural beauty in China
}

\author{
Shzr Ee Tan ${ }^{1}$
}

Received: 1 January 2020 / Accepted: 10 February 2020 / Published online: 10 July 2020

(C) The Author(s) 2020

\begin{abstract}
Places of 'scenic beauty' in China-national parks, panda enclosures, holy mountains, private gardens-have been sites where encounters with nature have been constructed through idealisations of particular ecologies. Often, in these environments, the sonic design of space predicates as much on 'organic' elements as on deliberately-engineered and broadcast 'artificial' sounds. Loudspeakers are hidden in trees and rocks. Broadcasting ambient sounds throughout the course of the day, they send signals ranging from Chinese classical music to spoken descriptions of local objects of interest, to exhortations to walk in an orderly fashion, to religions chants. Sometimes, the broadcasts are presented in overt articulations in invocation of public service announcements or tourist information posts. Based on multi-sited fieldwork in Northern, Eastern and Southern China, this paper considers such mediated soundscapes along four axes of analysis. First, I contextualise such sonic 'atmospheres' within surveillance culture in China and civic instruction through public address. Second, I examine them within a longer, well-known history of Taoist philosophy that positions man in relationship to the cosmos through a perspective of 'artifice' embedded in oppositional co-existence with 'nature'. Third, I explore these articulations as multisensorial experiences found in ecotouristic brands. Finally, I critique these sonic mediations in interaction with perceived 'natural' sounds within broader theorizations of ecomusicology developed by Guy (Ethnomusicology 53(2):218-248, 2009) and Rees (Ethnomusicology 60(1):53-88, 2016), coming to conclusions on national vs local acoustic ecologies of the 'natural' Chinese world.
\end{abstract}

Shzr Ee Tan

shzree.tan@rhul.ac.uk

1 Royal Holloway, University of London, Egham Hill TW20 0EX, UK 
Keywords Ecomusicology $\cdot$ Ecotourism $\cdot$ Civic education $\cdot$ Taoism $\cdot$ Chinese temple

\section{Introduction: bamboo birds, electronic blessings and orchestral-recorded lakes}

FOR THE hundreds of daily devotees and tourists making an autumn pilgrimage to the holy site of Hangzhou's third-century Lingyin Temple [Lingyin Si一灵隐寺], the path to Buddhist contemplation is laden with moss-skimmed paths, pebbly streams, falling leaves, ancient Buddhas carved into walls - and ebullient birdsong. Heard in multi-layered performances of gurgling trills and sinuous melodies, these delightful, intertwined tunes are competitive in their repetitive stridence and shrillness. But all is not as it seems: as one moves in on closer approach to the temple itself, the 'birds' are revealed not to be perching on tree branches or even sitting in gilded cages. Instead, they are the making of enterprising craftsmen-turned-touts. Guarding the main entrance to the temple, these men and women carry on their bodies small satchels containing souvenir bamboo whistles (See Fig. 1a). These tiny instruments they actively and repeatedly toot—against each other and to incoming visitors-in simulation of the calls of hyperactive birds tweeting into the natural soundscapes of rustling forests and flowing water. It is all, surely, pastoral and idyllic-but also an attention-grabbing sales pitch.

The artifice of such calculated and humanmade musical performances of nature inspires mild amusement - even joy - in the temple visitor, herself (in my case, as author) already charmed and awed by the blending of artistry seen in the ancient Buddha reliefs enshrined in grottoes and cave walls. But the artifice does not end. Moving past the whistle touts to queue up for tickets and officially enter the imposing temple and its many buildings and annexes, one is confronted with a row of at least ten shiny new metal turnstiles. For a small fee of several tens of renminbi (a couple of US dollars) one obtains a stub that is read by a scanner attached to each turnstile, which sets off not only a physical rotation mechanism allowing the visitor to gain entry to the space, but also an electronic greeting of a male voice hailing 'Amitabha'. As queues of people pass through the temple gates, random chains of electronic Buddhist blessings, heard in staggered and sometimes bunched-up succession, reflect the rate of entry of men, women and children into the vast temple complex. This in itself is a magnificent feat of human artistry, architecture and engineering set in a stunning valley in one of China's reputedly most beautiful regions of natural scenic beauty.

Inside the temple complex, piped musics of different varieties and sources continue to be heard. A conservatory-souped-up version of jiangnan sizhu (江南絲 竹-silk and bamboo music from Jiangnan) is played in a shop with open-air corners; longer Buddhist chants sung by (one assumes) monks and nuns are broadcast from ghetto blasters outside some of the key shrines on site (Fig. 1b). Meanwhile, as tourists walk around in groups across the 16-ha complex, pop-music-memes for ringtones activate here and there, even as visitors make selfie celebratory and 
Fig. 1 a Bamboo bird whistles. b Buddhist chants mediated from ghetto blasters
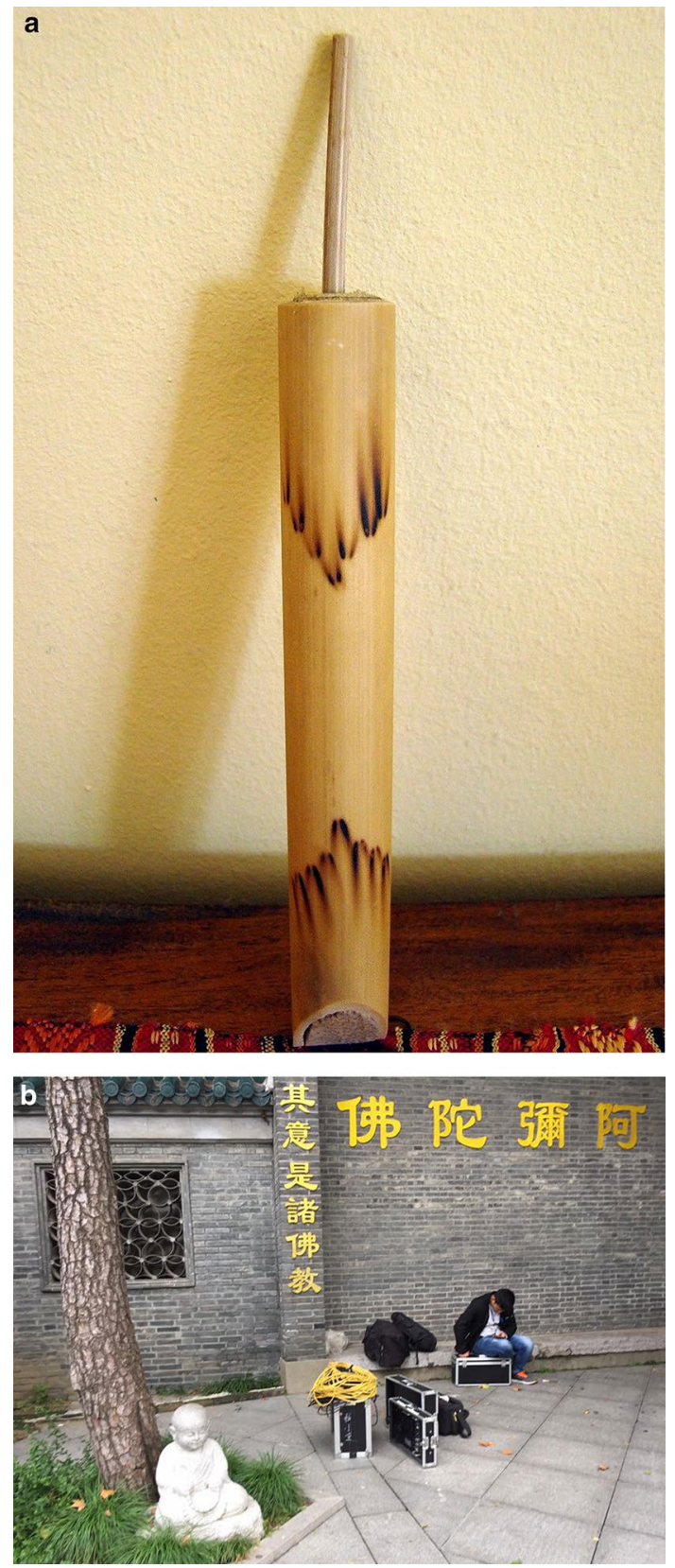

exhortative videos of themselves in the natural surrounds and replay them instantly in loud aural sharing and video viewing. A couple of kilometres away from Lingyin Temple on the banks of Hangzhou's celebrated West Lake, Chinese orchestral music is also broadcast self-referentially over a teahouse's PA system, as tourists sip 
tieguanyin brews on a wooden, open-air pavilion while they cast their eye over the serene waters in late November, listening to the well-known hit tune, Pinghu Qiuyue (平湖秋月一Calm Lake and Autumn Moon).

But Hangzhou is not the only spot or region where these sonic interplays take place. Scenes as such-of mediated and electronically-amplified sounds situated in, interacting with and ventriloquising for the organic environment-are becoming ever-common articulations across China, from the holy Mount Hua in Shaanxi (华山-Huashan) to public parks in Shenzhen. More specifically, I argue that such sonic interplays are deployed by different agents (state and local governments, religious institutions, commercial enterprises) in strategic ways by which human encounters with nature have been deliberately constructed through idealisations and romanticsations of particular Chinese ecological and cosmological understandings.

The sites of these encounters comprise a specific genre of tourist destination known as 'places of scenic beauty' [自然美景-ziran meijing]—national parks, panda enclosures, holy mountains, even private gardens. Often, in these environments, the sonic design of space predicates as much on 'organic' elements as on deliberately-engineered and broadcast 'artificial' sounds and musics. Megaphones are frequently hidden in trees and rocks. Emanating ambient sounds throughout the course of the day, they send acoustic signals ranging from Chinese classical music to spoken descriptions of local objects of interest, to religious chants, and recorded exhortations to visitors to walk in an orderly fashion in the designated 'green' zone. Sometimes, the broadcasts are presented in overt articulations in invocation of public service announcements or tourist information posts.

What do these electronic mediations of/ with nature indicate of programmatic approaches towards parsing nature musically, in a digital age, in China? Can we say more in these case studies from China beyond relatively well-documented writings on foregrounded vs background music, as written about and taken for granted in the worlds of musical advertising and sonic branding (Sterne 2003, p. 327, Taylor 2012)? How do these mediated 'natural' acoustic experiences chime in with current thinking on ecomusicology, whether in relation to sense of place and environmental politics (Rees 2016; Guy 2009), or to anxieties over climate change (Allen 2011; Pedelty 2011; Allen and Dawe 2015)?

Based on multi-sited fieldwork in Northern, Eastern, Central and Southern China from 2011 to 2019, I attempt to gather a few case studies for discussion and answer some of the questions put forward. I consider mediated soundscapes along four axes of analysis. First, I contextualise such sonic atmospheres within a longer, wellknown history of Taoist philosophy that positions humans in relationship to the cosmos through a perspective of 'artifice' embedded in oppositional co-existence with 'nature'. Second, I examine them within the frameworks of surveillance culture in China and civic instruction through public address mechanisms, looking at broader issues of acoustic disciplining and government policing of behaviour through sonic interventions. Third, I explore these articulations as multisensorial experiences of spectacle found in ecotouristic as well as self-essentialised nationalist 'place' brands. Finally, I critique these sonic mediations in interaction with perceived 'natural' sounds within broader theorizations of ecomusicology developed by Guy (2009) and Rees (2016), and also locate them within wider debates about public spaces, 
personal agency, the rise of the anthropocene and looming environmental crises. Thereafter I come to conclusions on global vs national and local acoustic ecologies of the 'natural' Chinese world.

\section{Historico-cosmological/philosophical constructions of oppositional harmony between human artifice and nature}

The dynamic relationship between human and nature, or human versus nature is a trope that has been observed in many different geocultural and historical contexts around the world. This includes diverse indigenous mappings (Feld 2012; Magowan and Neuenfeldt 2005; Tan 2013) around the world of symbiotic mutual reliance between humankind and the environment (including, also, their subject to historical and contemporary romanticisation), as well as Darwinist viewpoints of the Enlightenment relocating such binary relationships within broader hierarchies of evolution and species-organisation. From a Chinese historical and cosmological view, philosophical constructions of oppositional harmony between human artifice and nature have been in existence since the fourth-century. These have been inscribed in oftheard tropes about complementary binaries and merging ternaries seen in, for example, the emblematising of Daoist and Confucianist concepts of the Yin/Yang [B月/阳] duality, or the Tian-Di-Ren [天地人] Heaven-Earth-Humankind trinity (Li 2011; Ames 1984).

Indeed, the positioning of the human in nature as a specific demonstration of successful environmentally-blended artifice-while not always presented as a consistent and straightforward relationship across different eras, geographies and cosmological beliefs - is one which reappears in much Chinese literature, art and architecture. A well-known example is the strategic erection of a single-person's chess pavilion on a cliff edge off the dramatic, holy Mount Hua near Xi'an, a site of many ancient and contemporary Daoist hermit pilgrimages (Fig. 2). In even conceiving to build (never mind scale) this architectural folly, the potential terror and difficulty of carting sculpted stone to a vertiginous spot only to later provide for solitary contemplation of an intellectual game held in 'mid-air' mountainous suspension, provides structural evidence of humanity's awe for-and also tribute to-nature. The idea, one surmises here, is to find quietude in nature, but in so doing changing-even upsetting - the quietude by inserting oneself and human artifice into the schema, thus inspiring a new kind of mutuality and dynamism. Is the human element, then, now subsumed within the greater majesty of nature in the organic fusing of self into the rock? Or, has nature's greater powers instead been 'tamed' by humanity through the poetry and expression of sympathetic but all-conquering architecture?

Beyond architecture and moving intermedially into the world of visual art, sonic parallels of the same philosophising approaches can be seen. A Qing dynasty scroll by $\mathrm{Yu}$ Zhiding (See Fig. 3) for example depicts an classic landscape of bamboo groves and a hillside. Nestled into the idyll is a lone qin (Chinese zither) player sitting on a rocky ledge. His communing with nature-the open weather, huddled pine grooves and one imagines, birdsong-brings to mind a sonic placing of self 


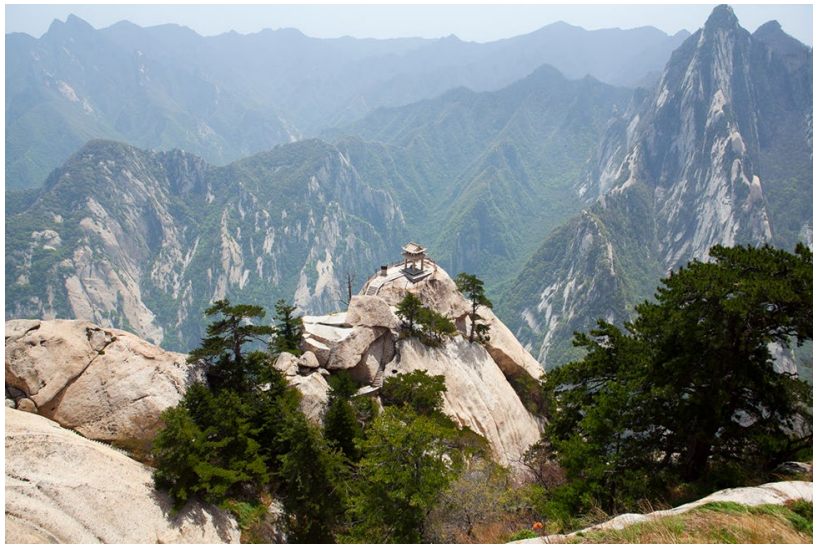

Fig. 2 Chess pavilion, Huashan

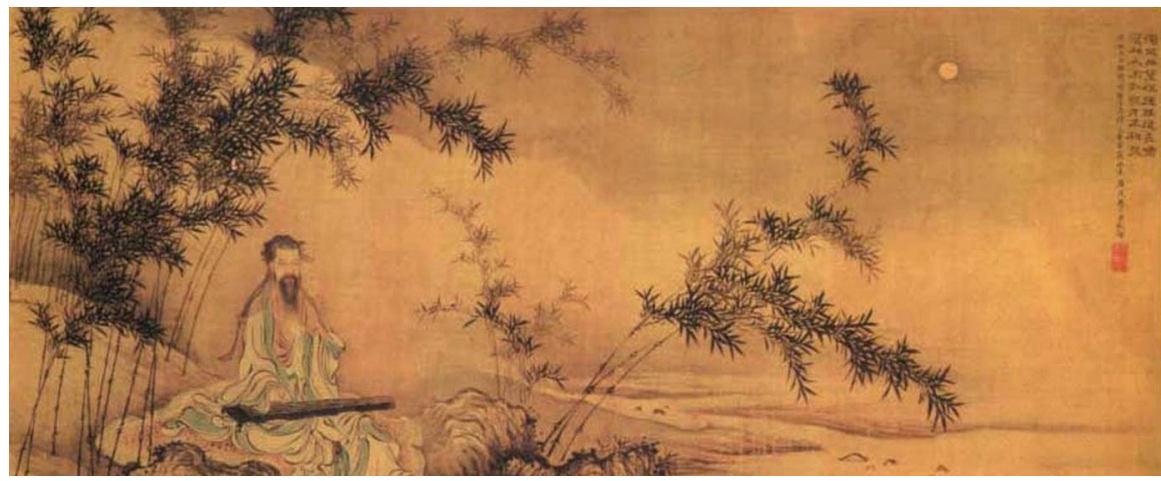

Fig. 3 Yu Zhiding, Qing Dynasty scroll featuring Guqin player in wilderness

and instrument in the soundscapes of the wilderness. In fact, the qin player might very well even be playing a musical imitation of nature via programmatic tributes to flora and fauna, delivering famous pieces in the qin repertoire such as Meihua Sannong (梅花三王一Three Strands of Plum Blossom) or Gaoshan Liushui (高 山流水-Flowing Waters from Tall Mountains). Such hermit-like, solitary musical engagements are a frequent feature of musical traditions in East Asia, the effects of which have been described in Andrew Killick's (2006) coining of the term of 'holicipation', where music-making is often embarked on with a view to seeking mindful and personal satisfaction of 'the whole of the musical event' with 'only the performer and listener involved.' In many of these cases, the presence of the larger, bigger-often natural-environment becomes a critical part of the eventmaking. Beyond China, Joseph Browning (2017, pp. 171-192) have Elliott Weisgarber $(2019$, pp. 17, 29) also theorised about shakuhachi flute players who practise co-performance with nature in (semi) natural settings of Zen gardens or bamboo 
groves. As to whether these sonic end products are deemed human-made, 'natural' or even celestial is up for deliberate debate in specific Chinese classical worldviews. One could for example easily invoke here fifth-century philosopher Zhuangzi's [476-221] pronouncements on harmony in the cosmos as attained through the playing of pipes and channelling of music through ritual (Brindley 2012; Lam 1998), thus feeding into a psycho-cosmology of universal peace as to be ultimately found in the meeting of human and natural/ heavenly orders, and where balance is finally found between chaos and order.

To be sure, modern manifestations of such tropes of complementary and opposing binaries are the result of historicised constructions of the past and of Chinese sagedom, even as they may have been understood differently throughout different periods of Chinese history. (Puett 2002). The point, however, stands that contemporary thinkers - and appreciators of music and nature in China - still choose to understand this human-nature trope of mutual binding in particular ways. I argue, further, that there is material evidence of this way of thinking in contemporary articulations of architectures of mediated sounds in contemporary Chinese examples.

Where the two examples of a mountain-top chess pavilion and a qin player in the woods are well-known in Chinese art history, further examples can be foundnot only in historical paintings and accounts of featuring musical picnics (Picken and Nickson 2007), but of actual, continued existence of these soirees-in-nature in large and small ways. These include increasingly amplified Hua'er festivals held on the foothills of Gansu's Lianhuanshan (莲花山-Lotus Flower Mountain) and other slopes, where singers in the outdoors trill out strands of folksong featuring sexuallyeuphemistic lyrics with metaphorical references to flora and fauna. Singing to backing tracks, they carry their own sound systems and hooked-up microphones which blast amplified, live and recorded sounds on hiking trails and mountain tops. All across China, in the heart of leafy city- and community parks, singers, instrumentalists and dancers-whether enthusiasts of local opera, dilettantes in storysinging genres, practitioners of folksong, or fans of pop-based guangchangwu (广场舞一 open-field mass dancing, largely carried out by women as aerobic exercises)—-thrive and prevail. On holy sites from the more well-known Mount Hua and Wutaishan [ 五台山], to every city's local 'hillside attraction', tourist-friendly concretized stairs leading to small, enshrined temples or monasteries are more often than not equipped with hidden PA systems that also play a range of Buddhist chants and appropriatelythemed nature-friendly classical music to enhance the outdoor experience of climbers and day trippers. This I have observed in sites from Xi' an to Gansu, Yangzhou, Shanghai, Suzhou, Chengdu, Beijing and Shenzhen. While the specific situations of each case of sonic remediation of nature are different (as I will demonstrate in some examples below), it is important to note that these manifestations-of artifice and construction, in the more contemporary guise of amplified and electronic soundhave deep historico-philosophical underpinnings. 


\section{Civilising projects in China via public instruction and social conditioning}

Digging deeper into the classical interpretations of sonically-mediated 'nature' described above, one can often detect a distinct embedding of didactism, connotated directly by the presence of Confucian, Daoist or Buddhist doctrine and dogma implied in the cosmological underpinnings of the human-nature binary. In contemporary Chinese political contexts, whether in national, regional or local governments, this didactism often presents itself in the rolling out civic projects with civilising agendas. Made on behalf of the Chinese government, such efforts of public moral instruction conflate traditionalist tropes of gentle education for the edification of society and humanity at large, with the specific efforts of the Chinese Communist Party in encouragement of aspirational self-cultivation for nationhood across the masses (most recently seen via President Xi Jinping's vision of China Dream一中国 梦-Zhongguo Meng).

Other such civilising efforts are most frequently seen in the soft policing of public spaces and public behaviours through the ubiquitous and systematic deployment of public signage throughout China (Fig. $4 \mathrm{a}-\mathrm{g}$ ). A few notable examples come to mind: exhortations to keep off the grass on local green tracts are painted on wooden plaques studded on lawns proclaiming, in cutesy fonts and graphics, 'Please don't step on the green grassland'). Washroom hygiene is promoted via the questionable paraphrase of astronaut Neil Armstrong's 'A small step for a man; a giant leap for mankind' found outside many public toilets. Organic and calligraphic-looking ribbons of colour swirl around the more politically-explicit 'China Dream' in advertisements for the state telecommunications (and some say surveillance) company China Telecom. Often deploying rhyming couplets or the use of complex, flowery language, these inciting catchphrases are almost poetic in their persuasion and delivery. Indeed, one can argue sometimes that a very thin line exists between such appeals towards the better instincts of humanity, and that of state propaganda (seen for example in popular cartoon and smiling depictions of friendly policemen who preach good citizenship and civil behaviour across Chinese cities, parks as well as public and private buildings and spaces).

The sonic manifestations of these civic instruction campaigns can be found in just as many-if less immediately noticeable-instances throughout China. Here, they appear as a matter of both state-originated and corporatised behavioural policing-turned-surveillance, and function as a form of acoustic disciplining. In Sichuan's historic and majestic scenic spot of Dujiang Dam [都江堰] on Mount Qingcheng, for example, a seven-foot video screen stationed at the foot of a hiking trail littered with falling golden gingko leaves is itself playing videos of falling golden gingko leaves. The moving footage is screened in between a scrolling text announcement that delivers-as well as broadcasts aurallya gentle admonition to hikers to stay on the beaten path, move in number of at least two persons, and to respect the countryside by depositing all litter in bins. These aural announcements, made by a mellifluous female voice, are in turn spoken against the recorded backdrop of light Chinese orchestral music, making the 


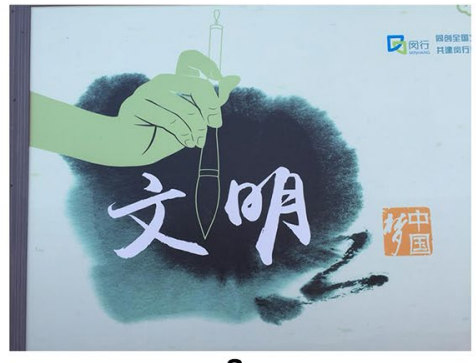

a

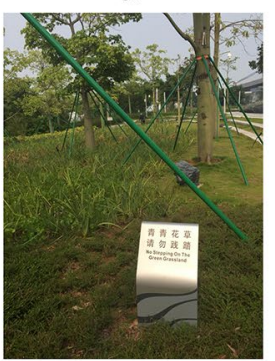

C

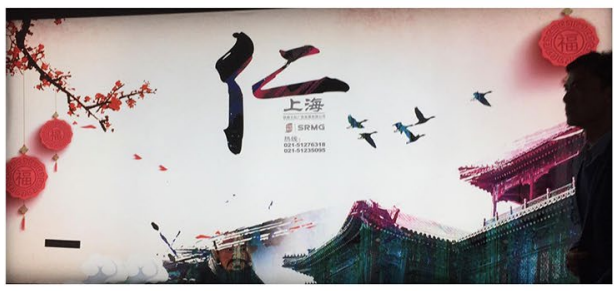

e

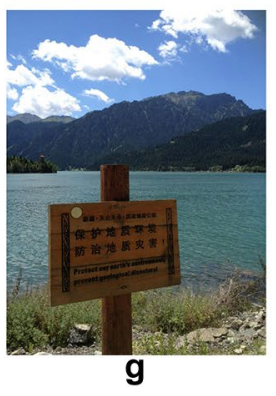

Fig. 4 a-g Public signs across China

whole performance a recording within a recording. Against the gentle musical strains, the stern and didactic aspects of the message are tempered aurally and sensorially.
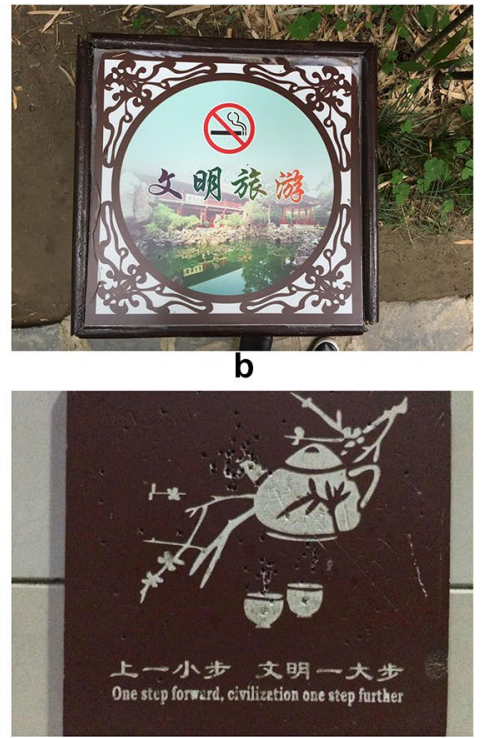

d

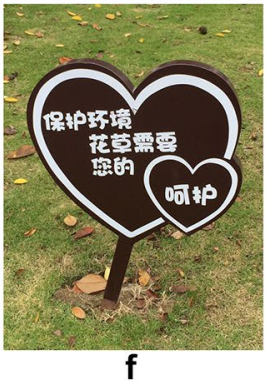

f
Fig. 4 a-g Public signs across China 
Sichuan is not the only site hosting manifestations of sonic didactism via experience of nature, of course; 'such instances can be found in different guises throughout the whole of China today. Returning to Hangzhou, for example, where visitors have to queue up for tickets to enter Lingyin temple, electronic aural blessings of Amitabha are set off alongside the pushing of turnstiles subliminally suggesting that visitors assume a respectful state of mind when entering a sacred site set in a lush, green zone. Pedagogy, religion, nature and human passage thus all meet in the same cosmological instant of this electronicised and sounded ritual space. On West Lake itself, an electronic greeting in Mandarin somewhat sternly informs the visitor that 'You are entering the Xihu Scenic Zone'. The use of the word 'scenic zone' (景区jingqu) implies several things: that a self-contained sight of official, great beauty is soon to be upon the eyes of the visitor; and that a specific set of behavioural restrictions (or civilised, positive actions) are to be applied within the confines this designated space-whether in dedicated awe and appreciation of the beauty of the lake, as many visitors do with selfies, or in a commitment to not defile the environment with litter or noise. What is ironic here is that the stridency of the electronic greeting message alters the affective dynamics at play: the vocal suggestions seem almost counter-intuitive to their meta message of generating civilised restraint.

A tangential anecdote can be made here of my observation of sonic disciplining at work and general disciplining of public behaviour on the Chinese mainland, in comparison with a few instances casually remembered from fieldwork and visits to the Chinese diasporic territories of Hong Kong and Singapore. Where instruction in China appears to be couched in generally polite requests that are roundabout and more benign in their soft-policing of behaviours (one assumes in lyrical complement to the pastoral or green atmospheres of these sites), the admonitions to follow rules appear to be more clearly and severely articulated in Hong Kong and Singapore. In the latter territories, admonitions frequently begin with an explicit 'Do Not... Smoke/Litter/Play Loud Music/Eat Durians'. These also often feature the iconic depiction of an activity being banned in its being over-written by a red circle and a diagonal line. The only exception I have observed so far in China involving a direct, negatively-worded prohibition was a request not to disturb sleeping, precocious baby animals at rest in the panda reserve in Wolong, Sichuan. And even here, such signs - visual invocations requesting acoustic disciplining via a forefinger held in front of lips (Fig. 5) - were placed alongside cute anthropomorphic panda icons, with short preambles in other parts of the reserve providing more detail on why the panda environment needed to be kept in situ and as in its 'natural state' as much as possible, with minimal human disturbance from tourist action.

Such carefully-worded and delicately-couched aural entreaties (as well as visual suggestions to respect aural spaces) may hint at wider undercurrents in relation to mainland Chinese approaches towards soft-policing public behaviour amidst the rapid urbanisation and industrialisation of the Chinese countryside. These in turn have roots in the steady rise of a new middle class and new 'wealthy peasants' [ 土豪-tu hao] coming to terms with changing experiences of nature (as opposed to agriculture), and new experiences of ecotourism as geographical forms nationalist 
Fig. 5 Sign, Panda Enclosure, Sichuan

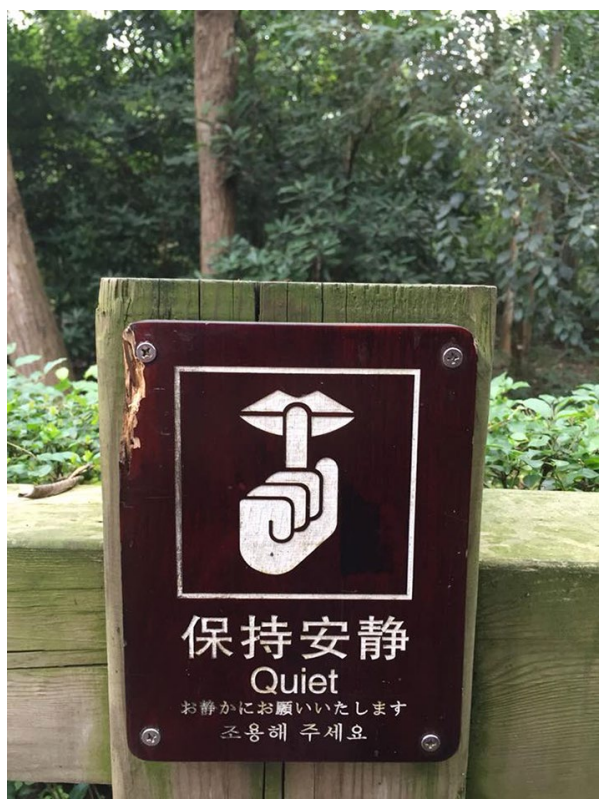

grandstanding. In such instances the disciplining rhetoric is ideological, gentle and poetic even, pointing towards a deceptively-subtle deployment of propaganda. Rather than explicitly imposing fines or penalties (as is true and well-known of Singapore such that prohibitory announcements have become memes on fridge magnets), an appeal is made towards the would-be cultivated, potentially bourgeois and aspirationally learned instincts of the users of parks and visitors to scenic spots. In channelling 'civilised' methods to preach 'civilising' and 'civilised' behaviours, such drives are ideologically consistent, class motivated and strategically nationalistic. Looking at such public calls for 'good citizenry' on a broader level, it is not unfair to suggest that civilising schemes across China have been deliberately implemented to combat rising reports of badly-behaving, unchecked and allegedly 'uncivilised' Chinese tourists thronging scenic spots domestically and beyond. ${ }^{1}$ It is no surprise, then, that attempts at national face-saving in the emergence of such delicate and class-underlaid phenomena have also been designed with equal attention paid to class-sensitivity. To this end, the practice of nature-channelled, 'civilising' sonic intervention has no doubt been subtly and aptly deployed.

\footnotetext{
1 'Rude Awakening: Chinese tourists have the money, but not the manners.' South China Morning Post, by Amy Li, December 31 2014. https://www.scmp.com/news/china/article/1671504/rude-awakeningchinese-tourists-have-means-not-manners Last accessed Dec 30 2019. 'Have the Chinese replaced Americans as the worst tourists in the world?' Vice, by Gavin Haynes, May 29 2013. https://www.vice.com/da/ article/gqnzxj/are-chinese-tourists-the-worst-tourists-in-the-world, Last accessed Dec 302019.
} 


\section{New eco-tourisms: artifice in nature as self-essentialist national spectacle}

Where tourist experiences have become explicitly nationalistic affairs, one particular category of exhibitory extravaganza is the site-specific multimedia spectacle, set outdoors and constructed within naturally occurring sites of scenic grandeur. Known by the Mandarin term of shijing biaoyan [实景表演], or 'live scenery performances', these large-scale musical variety shows deliberately turn splendid landscapes-from the Jade Dragon Snow Mountain in Lijiang Impressions, to recreated 'Mongols' galloping across a lake surface in Kaifeng Millennium Park, and Huaqing Palace turned alight in Xi' an-into backdrop objects of wide-angle gaze. In many such performances, sound design-mostly prerecorded, amplified and featuring orchestral and synthesised tracks which are lip-, hand- and motion-synched-is tailored to the pageantry and spectacle of each performance. The sonic expressions do not so much remediate 'natural' or 'organic' sounds in the programmatic approaches described above (of qin repertoire for example), than metaphorise and exaggerate the grandeur of nature's stunning attributes through a deliberate celebration of its presence. This is achieved through out-aweing the breathtaking qualities of nature itself. Here, nationalist constructions of geography and natural architecture are troped for domestic tourist audiences. As stately landscapes found only uniquely in China, these sites become specifically identified as Chinese symbols of place, space and power.

In November 2017, I attended Yinxiang Xihu (印象西湖-Impressions of West Lake-now renamed Enduring Memories of Hangzhou) in Hangzhou, an hourlong site-specific presentation of light, sound and mass-display humans-as-props. First created by the film director-turned-dramaturg Zhang Yimou as a showcase presented to VIPs at the 2016 G20 Summit, the large-scale show is now a nightly ticketed event made available for the domestic Chinese masses who sit and enjoy the performance in the semi-open air on raked seats under a high canopy. Beginning under the cover of darkness on a gated-off section of West Lake, the show opened with the mood spotlighting of distant pagodas and bamboo grooves emerging one after another in slow glow to the accompaniment of a quiet, mysterious guzheng zither soundtrack. As the show progressed new, eye-catching set pieces loomed into view, including a multicoloured half-moon bridge and a lantern-lit floating barge, each of which fused visually into different sections of the lake Against these ever-overwhelming backdrops, rows of elaborately costumed human dancers moved in mass formation. (Fig. 6a). Accompanying the presentations was a wide selection of pre-recorded music. This ranged from amplified solo guqin pieces to conservatoire-arranged Chinese ensemble music, a Tchaikovsky ballet excerpt, regional folksongs belted out in Western operatic style, synthesised orchestral tracks, solo piano music (featuring the heavy lifting of a grand piano onto the lake surface (Fig. 6b) and a breathy female solo songstress singing against a keyboard.

At one high point of the performance, corps de ballet dancers in tutus and flesh-coloured tights twirled their own version of a mass dance routine on the 


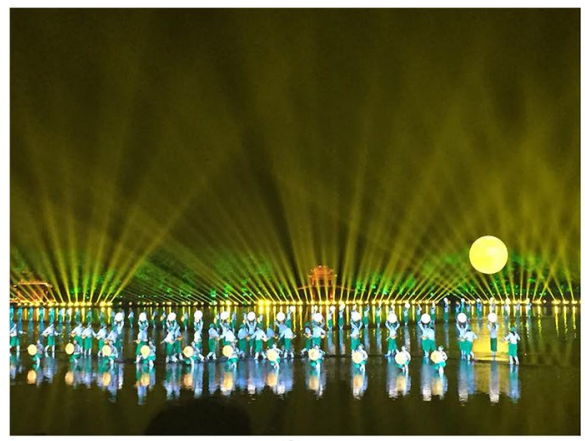

a

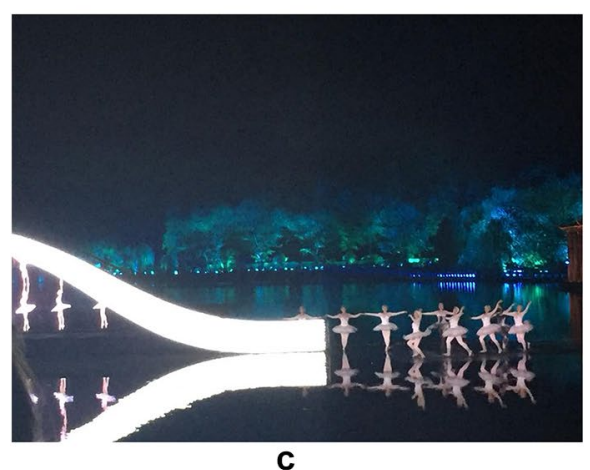

C

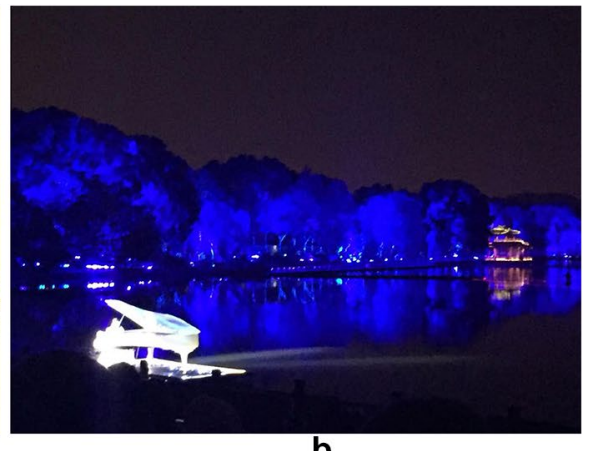

b

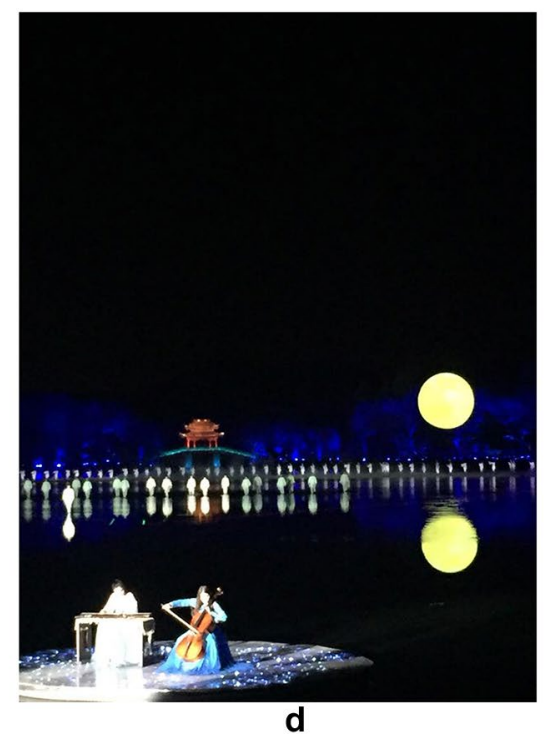

Fig. 6 a-d Scenes from Impressions West Lake

surface of a Chinese Swan (West) Lake, while an illuminated screen image took the well-known Odette final solo, pirouetting in the glare of swirling lasers streaming in the background (Fig. 6c). In yet another tableau, a cellist and a zither player rose apparently from the depths of the lake on a floating lotus-leaf stage to hand-synchronise movements to an amplified soundtrack of high-volume crossover pentatonic pop (Fig. 6d). The grand finale was a slow procession of performers carrying colour-changing lanterns in interweaving lines on the water's surface. In this pageant-like closing item, loud strands of choral and synthesised symphonic tracks played slowly and steadily to a picture-perfect finish. 
The intended effect-with ever-more spectacular scenes shifting from frame to frame-was a celebration of the already magnificent beauty of the natural environment as place (West Lake), through an over-the-top enhancement of it for the ultimate consumer experience. Interspersed between the light and sound displays were narrated speech elements that detailed some of the stories behind well-known flora, as well as humanmade architectural additions to the lake. In poetic language, the latter elements were described as specific ornamental improvements to the 'organic' site: a bridge over a passage of water was likened to an embroidered silk belt on a human torso; a pavilion nestled amongst local foliage was analogised as a lady's hairpin. These anthropomorphic characteristations of artifice in nature, in turn, were also prefaced with their dates of constructions (and by which prominent political figure) within broader narratives of the history of Chinese civilisation. Mirroring the Chinoiserie visual tropes of dragon gates, fluttering martial flags, spinning paper umbrellas and even a fake moon featured in the show, these commentaries-together with light, sound, music and natural architecture-worked to deliver a theme-parkinspired and unabashedly nationalistic vision of West Lake. No doubt, the site had to be given due celebration as a distinctly Chinese emblem in its self-essentialising scenic specificity.

Such presentations of affective sumptuousness and theatricality bring to mind recent political commentary on the deployment of soft power at the Beijing Olympics Opening Ceremony in 2008, where the event helped 'invoke discourses of similarity in the form of Western economic development models and difference in the form of essentialized tropes of Chinese culture to counter global images of China as a threat to international well-being' (Hubbert 2013, p. 408). It also echoes earlier critiques of the staging of Turandot by Zhang Yimou in the Forbidden city as spectacle mobilising 'the aesthetics of the excess to create an intercultural Fantasy Island' (Metzger 2003, p. 214). As cultural showcases in which landscape is a subject in itself and is performed metaphorically and physically, these opulent displays in China have over the years developed from cultural diplomatic efforts of international grandstanding via 'art' to internally-focused nation-building campaigns. First constructed to impress overseas audiences, such 'live scenery performances' of nature in artistic and mediated extension have now been adapted to meet the tastes of an ever-expanding domestic tourist market, increasingly attuned to celebrations of national pride and regional exoticism via in the channeling of a new, fetishized Chinese-style eco-tourism. Indeed, some of these shows even advise viewers (via online websites and ticket-stub fine print) to read up on local histories and the local environment before they turn up for each show, so as to maximise each full experience. In the words of Jennifer Hubert again, these performances have reframed culture 'as a mechanism through which the commodity spectacle was, albeit perhaps paradoxically, used to produce moments of national collectivity for intellectuals in contemporary China.' (Hubbert 2010, p. 119).

One might at this point take a small step back from the imposed appreciation of such awesome display, and make tentative attempts towards contextualising some of the extravagance thus exhibited in terms of preliminary environmental and aesthetic critique. Indeed-while the larger-than-life element of nature has itself become a subject of the show such that it was to be out-performed and 
out-amplified by relentless streams of artificial light and sound, in practical reality the show's ticket-paying human audiences remained sheltered from nature's most terrifying elements per se, taking in the sights from rows of raked seating under a canopy, away from the wind and rain. Screened off in the confines of this 'safety zone' in hats, scarves and warm coats, these spectators could cast a (selforientalising and anthropomorphic) gaze upon nature at its most spectacularmore often than not looking at it, and capturing it from the frames and screens of their mobile phones as they filmed entire segments of the show to upload later onto the internet and/ or share with friends on social media. The multimedia aspect of spectacle has, thus, become further multi-mediated across different timespaces.

From a logistical standpoint, the lake in its full glory had also been cordoned off indefinitely such that an entire section of it was only now viewable by night and by paid ticket. An inevitable result, thus, was not only the interference of heavy-intensity light and sound in the making of show theatrics in West Lake's otherwise fabled natural environment, but also the concentration of heavy tourist foot traffic in one specific section of the site at an otherwise relatively quiet time of the day. With each new appearance of a lighting flare prefaced by a magnificent boom or choral effect from multiple-decibel sound systems, rows of audiences 'oohed' and 'aahed' on cue. In my observation of Nov 2017, hours before the show began noisy crowds were already queueing up in droves around the scenic area, chatting and taking photographs. One could argue that acoustic disciplining here was now being enacted in the name of a newer, human consumer need for spectacular nature, even as managers of the site clearly spared no expense in their careful and conscientious maintenance of the green elements around the lake and its delicate ecosystem-key to the heart and branding of the entire project.

And yet, in spite of human interventions to and on behalf of the natural environment, perhaps nature could still find its way towards taking the final, bitter laugh. My own field investigation and tourist experience of going to the show in early autumn showed that sustained wrestling with $5{ }^{\circ} \mathrm{C}$ temperatures in November in China was no comfortable ride for anyone already wrapped up in a snug puffa jacket, sitting away from the wind and rain. Where did this, then, leave other human costs of such 'enhancement' or 'interference' with the elements (also for human-oriented appreciation)? As I watched from the relative snugness of my dry seat, rows of bare-shouldered ballet dancers in tights were visibly shivering in the open air and light rain as they pranced around on the water's surface, looking as if they would very likely be catching pneumonia the next day. As I sneaked a peek backstage immediately after the show, I saw a large number of performers scamper off stage as fast as they could and eagerly dive into the warmth of their padded jackets and boots. Herein lay the stark paradox of these entangled coperformances of the human with the natural environment: where the vicissitudes of weather and climate might flex its own muscles against corporeal fragility, the costs to both human and non-human accounts were surely borne as a result of the corporatist and nationalist need for consumption and governance in a fast-establishing age of the Anthropocene. 


\section{(Mediated) sound in multi-sensorial experiences as the ultimate consumer experience}

The critiquing of site-specific hyper-performed spectacles within state-capitalist and consumer-focussed frameworks can be further finessed through a fourth approach towards understanding nature in remediated sonic design: as an omnichannel stimulation of all the senses to produce the ultimate state of end-user experience and enjoyment. The rise of multisensorial experiences in China have been largely buoyed by the country's already-mentioned rapidly industrialising demographics which in turn have led to the unprecedented growth of new, expanding consumer bases all around the country in interesting phenomena that have turned domestic tourism and leisure industries into important boom businesses. A telling vignette found in the recently-rich and speedily built-up first-tier city of Shenzhen, in Guangdong, captures the essence of this consumer-oriented feeding frenzy of multiple senses for maximal pleasure as an example. Inside a multi-storey spa complex in the heart of the city known as Shuilifang, one can walk through a sauna straight into a massage parlour, where three masseuses can work on your body - the first on your feet, the second on your torso, and a third on your ears in a procedure known as candling. Meanwhile, a private TV screen attached on a limb to your fully-reclining massage seat plays your programme of choice, even as piped spa music spills out from everywhere across the entire floor. In the same room, other clients enjoying the same massage services can also be playing their own choices of programme on their TV screens. It is not only the senses of sound, touch and sight that are being engaged here: taste and smell make it to the same tableau, through roving waiters bearing menus and plates of food which one can consume while enjoying a massage. Mixing into the many aromas of deep-fried squid or steamed chicken (to name a few dishes) are those of essential oils and fragrances utilised for the massage itself.

Such a performance of sensory overload described above has similar equivalents in many sonic remediations of natural environments in China. Key to such multisensorial play is the idea of meta consumption at work: it is not enough to be in nature; one has to know that one is in nature, and experiencing it in multiple layers. Often, it is through sonic_-pre-recorded and electronic-remediations of 'nature' from a local authority (eg the park management, or site government) that one is told and reminded of this meta-experience. Here, the experience of nature usually also takes place in hyper- or double-heightened contexts of the sensibilities involved.

Thus, one can find for example Chinese orchestral music playing the self-referencing tune of Pinghu Qiuyue [Calm Lake, Autumn Moon] to encourage lunar and aquatic appreciation on the moonlit shores of West Lake described previously, or understand the simulacra-like placement of electronic signs screening yellowing leaves falling to gently- swaying musical strains in the midst of real falling leaves in the forests of Dujiang Dam on Mount Qingcheng, also already described. A third example of megaphones hiding in the shrubbery playing Grieg's Peer Gynt Suite can be found in Xinqinggong Park, Xi'an (Fig. 7), where 
Fig. 7 Speakers hiding in shrubbery, Xinqinggong Park, Xi'an

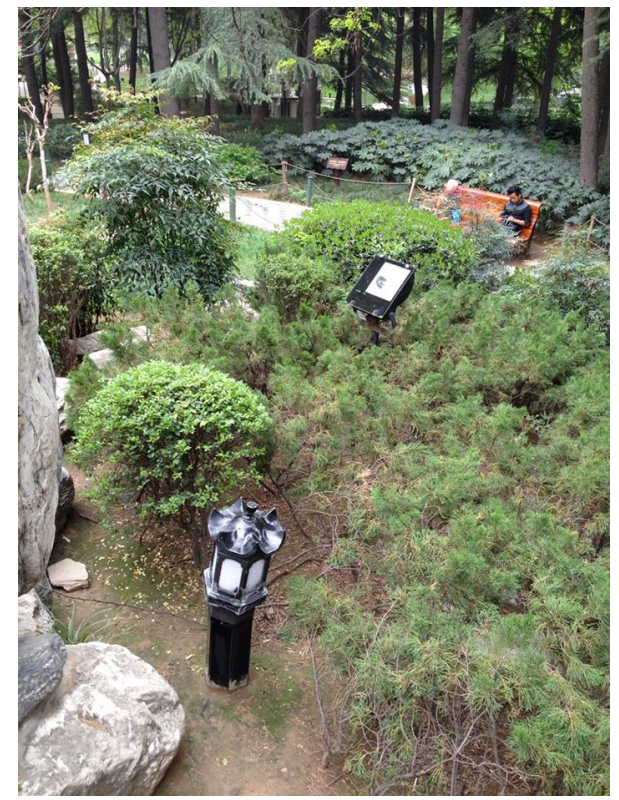

in 2013 I observed real birds tweet in the background, in competitive sounding against a third source of a musical fountain spraying forth watery jets and amplified recorded strains of Enya in a different section of the park. That was not including a radio blasting upbeat Chinese pop out of a souvenir shopfront nearby. In Yangzhou, an equally if not more exaggerated fourth example can be found in tour groups moving amidst specially-cultivated bamboo forests in Ge Yuan, a classical Chinese garden and scenic green spot (if artificially constructed) in the historic town on the Yangtze River. As one attempts to walk serenely between pillars of bamboo, contemplating 'nature' and straining to hear the chirp of summer crickets, a parade of tour guides carrying loudhailers provide running live commentaries (complementing visual signage) on the variety and strains of bamboo species specifically grown on site. Each guide leads his/her group through different shrubbery spots, their words weaving in and out of other stationary listeners' earshot as they wax lyrically about the beauty of this human-constructed green environment.

Such sensorial concatenation of mediated sounds from simultaneous sources brings to mind Adam Yuet Chau's evocation of the concept of honghuo [ 红火social heat] in his evocation of sensorial production of the social Shaanbei (Chau 2008, p. 494). It also echoes the Japanese idea of nigiyaka [にぎやか—cheerfully crowded boisterousness] in street festivals and markets. While it is easy to disparage the hyper-consumerist idea of omni-channel sensory intake as an undesirable effect of new Chinese economic advancement and insatiable hunger for new mediated experiences, one must also remember that pre-electronic acoustic musical precedents can be found in scenes more palatable and more easily-described as musico-pastoral. By this, I am referring to Chinese opera and folk performers who 


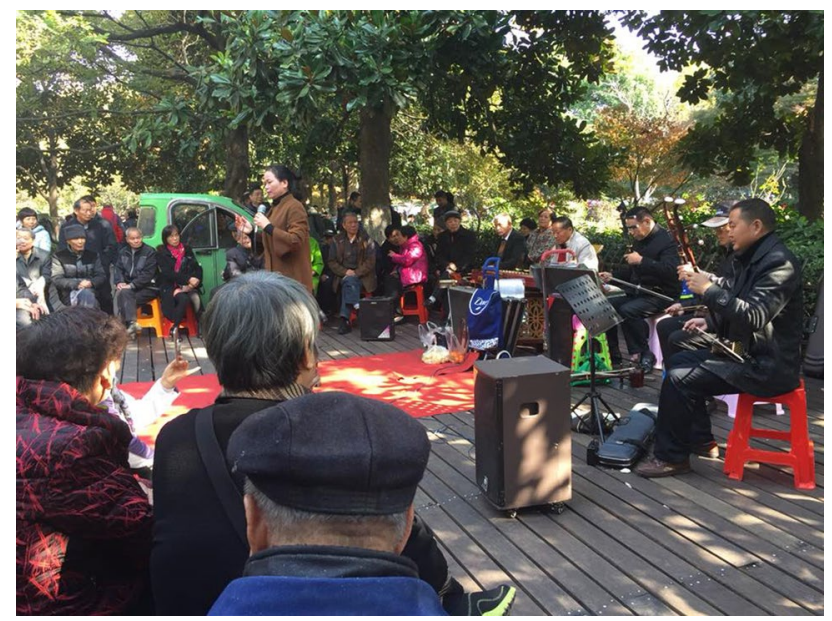

Fig. 8 Amateur amplified singers and instrumentalists by West Lake, Hangzhou

sing and dance in city parks, or Jiangnan sizhu [silk and bamboo] ensembles who rehearse or perform in the semi-open air in increasingly touristic teahouse pavilions. Increasingly, many of these performances have taken on electronically mediated dimensions.

The technologised extrapolations of such acoustic events is interesting for several reasons. Often, these re-articulations of nature and/ or acoustic sounds take place through the amplification of musical activities, found for example in the semi-staged set up of a group of folk singers I had observed in 2017 on the banks of West Lake amongst park shrubbery in Hangzhou. On this occasion, they were singing with accompanying instrumental ensembles in the course of an open-air concert using portable microphones and speakers (Fig. 8). At the same site in Hangzhou a few minutes later, I also spotted an elderly rollerblading dancer moving choreographically to a Chinese pop ballad broadcast from a portable boombox strapped to his body. With the soundtrack thus lined up to his bodily gestures and movements, he glided up and down bankside in deliberate exhibition of his grace and ability to anyone who was willing to watch and listen.

Away from Hangzhou, on a separate field trip conducted in July 2019 in the course of climbing the more remote and less-touristic Mount Lianhuanshan in Gansu with fellow scholar Frank Kouwenhoven, I was passed by many times by different (and much fitter) pilgrims as well as local villagers from the surrounding area who were also scaling the peak. These included ten or so singers of hua'er folksong who were carrying their own portable boomboxes, each playing a series of tunes ranging from hua'er with a pop beat to Buddhist chants. Sometimes, the amplifiers were used without backing tracks as unaccompanied singers simply used the speakers, connected to microphones, to electronically turn up the volume of their utterances. In the mind of Kouwenhoven, such displays made for disappointing and bleak comparison to his observation of and participation in hua'er activities almost two decades ago, where a whole mountain was resounding with hundreds of solo and 
duetting unaccompanied singers (Kouwenhoven 2006, p. 7). To be sure, in the same week on a different mountain near Lianhuashan, where a full-on open-air hillside festival was to be witnessed in another village in Gansu about a hundred kilometres away, a remarkable congregation of tens of thousands of singers had gathered to sing to themselves and each other amidst groves of trees in a forest, in a boisterous carnival of Gansu folksong. But even here, much of the singing had either featured an accompanying pop track, or was sung into a portable megaphone, or had invoked the use of a mobile phone recording device leading to the making - and almost immediate consumption after each singing session-of a musical selfie video.

Kouwenhoven interpreted the newer overwriting of pop tracks and unmitigated reliance on mediated sound in replacement of the rich, umamplified cacophonies he had experienced in the 1990s throughout China (Kouwenhoven 2006; Schimmelpenninck 1997) as devastating cultural loss. However, to my first-time mind and ears these experiences in Gansu were contemporary expressions of deliberately multisensorial worlds in China where technology had become an important prosthesis and proboscis for human interactions with immediate and wider environments. As such, the multiple and almost competitive strands of song sung simultaneously, as if emanating from different hidden valleys and summits of Mount Lianhuashan, appeared to me very much part of the experience of honghuo or renao (热闹 -liveliness) in context to the mountain coming alive in a different way, in a differently technologised time. Here, mediated human expressions were integrated into the natural soundscape of the mountain featuring more organic phenomena of gurgling streams, wind rushing through groves of trees, and singing birds, etc. In many ways, the portable boomboxes also allowed for the construction of different personalised soundtracks and background music to the wider activities pursued by the individual singers.

The phenomena of personal boomboxes brings to mind well-documented arguments on the self-curated sonic over-writing of sensorial experiences through portable, private and (often) hermetically-sealed wraparound worlds enabled through the invention of the Sony Walkman in 1979 (Bull 2001). However, at additional play here was a deliberately outward-facing and performative aspect of sound in relation to environment. The newer, portable soundtracks to one's life and its activitieswhether intentional performance, exercise, or mundane routine-were all played in public without the use of earphones; these sounds and musics were meant to be listened to by an external audience, and even strategically used to draw the attention of audiences. One could argue that such expressions make for a sonic staking of personal territory (in conquering a mountain by claiming it through sound, or in the competitive marking of amplified personal/ group space amongst competing hua'er groups, or in the general assertation of expressive identity.)

But sonic amplification - as expressed through megaphones hidden in trees-is not only made in extension of territorial scoping and expansion in aural claims of space and audience ship. Sometimes, the technology embedded in a tree, a shrub, a forest, or a mountain is constructed in a strategically veiled manner so as to deliberately obfuscate the source of origin: the speakers and megaphones are painted a camouflage green or decorated with artificial leaves very much like the antennas disguised as trees in Lisa Parks' description of 'concealment strategies' around 
technology which seek to mask their infrastructure organically ' as part of the built or natural environment' (Parks 2007). In such cases, technological mediation paradoxically enables the affective expression of the 'natural' by artifice. This invisibility —or at least aesthetic hooding — of sound here, bears implications on notions of agency, organicity, liveness and the seamless blending of human intervention in, enhancement of and extrapolation from the ecological environment.

\section{Concluding thoughts: public space, intersectional politics and crisis debates in 'Chinese' ecomusicology}

A revisit of the discussion embarked earlier on Chinese historical frameworks of dualities and trinities between human, nature and the cosmos can be made in complementary invocation of Aaron Allen's point that there are many kinds of intersectionalities involved in evolving ecomusicological debates, i.e. of the political, economic, cultural in conversations about the 'crisis of culture' (Allen 2011, p. 414). It is crucial here to see how sonic materiality is manifested and impacted by, but also has a negotiated impact in itself. In light of this, the binary relationship between human and nature in ecomusicology also has to be conceived of in further terms of the human and the state, the human and public(s), the human and economics, plus not least-the human and technology. Where, then, might the Chinese citizen, the public person, the Chinese consumer and the digital native stand or move in relation to evolving ecomusicological concerns vis-à-vis changing political realities increasingly revolving around debates of environmental crisis today?

Returning to the media re-creation of sounded natural worlds as civilising and public space-disciplining campaigns examined earlier, we have to understand these both as acts of policing by state-capitalist nationalist structures of Chinese governance, and also as grassroots-based assertions of personal space and sonic agency. Here, the organic actioning of these situations is sometimes further metaphorised and reinforced through invoking a 'natural order' as 'authority' in the co-option of the 'green' and wider non-human environment (whether in the troping of the natural environment as the default cosmos, or the default state of broader living existence). To recall an earlier example from West Lake in Hangzhou, one can argue that even as the rollerblading elderly dancer with his portable boombox might be heeding the park authorities' call to respect the natural beauty of the site in his aesthetic choice of a slow ballad for a soundtrack (as opposed to an upbeat techno track for example), he was also exercising an individual and personalised control of his immediate and extended physical and sounded world. As observed and discussed, this was further expanded through his performative and spatial invitation of viewership and listenership.

Where governments, tourist industries, media and Chinese corporate worlds may deploy mediated sonic materialities strategically to regulate public spaces in projects about/ in the environment, there is almost always a responsive (re)sounding of these motions by the individual citizen, consumer or 'Chinese member of public' who can use the same logics of sonic civilising and enhancement to experience the negotiated 'wholeness' of a space. Indeed, such responses from members of the public are 
Fig. 9 Roller blading dancer,

West Lake, Hangzhou

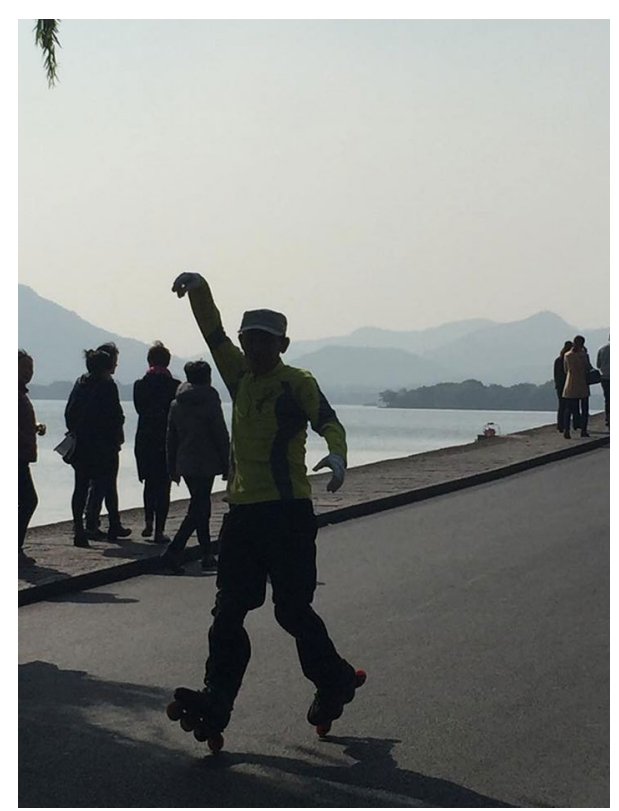

not always necessarily made as purely reactive contestations of space against the state-as-authority or nature-as-authority, or environment-as-authority. Triangulating different theories of interpretation explored in this article into interrogating notions of intent and agency, the rollerblading dancer (Fig. 9) of Hangzhou, therefore, might well see his own staking of sonic and physical space as a personal contribution to, comment on and magnification of the beauty of the lake environment. In the same way, the singing and instrumental party with sound systems in the same Hangzhou bankside park (Fig. 8) might view their pursuits as efforts of self-cultivation in engagement with local and traditional culture and histories, including the environmental and architectural histories of the West Lake.

The last two Hangzhou examples of public and electronically-mediated musicmaking in nature make interesting parallels with daily water calligraphers in the same scenic area, who can be observed practising their craft in the outdoors on the pavement by the lake, using DIY mops dipped in plastic buckets as giant brushes. Inscribing couplets directly onto West Lake's paved walkways, they stake their temporary mark on the environment by way of literally making poetic conversation with it. The ink, of course, is non-permanent and evaporates within minutes, echoing the Dao-Buddhist ethos of non-grasping the transient and practising wu wei [无 为-effortless action/ inexertion], while living fully in each moment-sensorially, humanistically and cosmologically.

Riffing off the theme of ephemerality, a bigger point can be made about public space as a default and authoritative framework, where invisible sonic materialities can be understood as temporary, ultimately disappearing occurrences in wider debates about environmental concerns, loss, permanence, ownership, stewardship and sustainability. In my own observation of Chinese train rides on city underground 
metro systems as well as intercity long-distance rail transits, I have observed the multiple and simultaneous public sounding of music videos, viral memes, internet advertisements, movie trailers and entire soap opera episodes inadvertently broadcast off the personal mobile phones of commuters, without the use of earphones. The preponderance of such multichannel 'incidental' sonic articulations, designed first for private and individual consumption but extrapolated by their audiences in the latter's claiming of sonic space within public contexts, sheds useful insights on sonic tolerance in China. An obvious interpretation would be to hear and analyse these multiple articulations under the ethos of honghuo and renao, or boisteriousness described earlier. A third, further reading would posit that all sonic utterances were ultimately ephemeral in their temporal materiality. In this final interpretation, any potential public sonic disturbances or claims on space would not have any longterm consequences.

And yet, this last strand of analysis can be further disentangled in yet deeper investigation of the organic ephemerality of sounded utterances within even wider debates about impermanence. As far as the electronically and artificially-mediated attributes of these articulations in and with nature in China are concerned, the irony is that many such temporary interventions are increasingly being recorded and captured for posterity as a matter of technological affordance provided by cheap and widely-available mobile phones. This is for example seen in the previously-discussed rise of musical selfies as well as tourist videos taken at multimedia shows such as West Lake and at hua'er festivals in remotest of regions in Gansu. Further examples come to mind as well, in the more orchestrated capturing or documenting of nature's sonic (alongside visual) moments in regional tourism campaigns, advertisements for corporations and brands using the natural environment as troped backdrop and soundscape, or in purely ethnographic albums and documentaries.

In my analysis so far of sound ecologies in China, I have yet to address the issue of environmental crisis and sustainability vis-à-vis the territory's alleged questionable public, pre-2017 track record for pollution ${ }^{2}$ and its government's more recent (and reasonable) refusal to absorb any more waste from the rest of the world, causing a secondary global recycling crisis. ${ }^{3}$ In the examples raised so far, with the exception of quietude requested in the Panda reserve in Sichuan, environmental safeguarding or climate crisis has not been a significant part of the conversation; most of the examples demonstrate a romantic or aesthetic troping of nature via the artifice of mediated sound woven into the textures of anthropomorphised green environments. To that end this paper is slightly different in tone, for example, from Nancy Guy's positioning of Chinese diasporic ecomusicology in her article on Sounds of the River Tamsui in Taiwan as deeply entrenched in debates about sustainability and ecological wisdom (Guy 2009). My article is also very different from Helen Rees'

\footnotetext{
2 'China's air quality worsens as national PM2.5 level rises 5.2 per cent in January and February.' South China Morning Post via Reuters March 21 2019. https:/www.scmp.com/news/china/politics/artic le/3002655/chinas-air-quality-worsens-national-pm25-level-rises-52pc, last accessed Dec 302019.

3 'The World's Recycling Is in Chaos. Here's What Has to Happen.' Wired, by Cheryl Katz, March 13,2019. https://www.wired.com/story/the-worlds-recycling-is-in-chaos-heres-what-has-to-happen/, last accessed Dec 302019.
} 
work on 'original ecology songs' in China, which investigates the musical linking of issues of rapid cultural loss with rising environmental loss (Rees 2016, p. 54). And yet, the questions asked by both Guy and Rees remain relevant to this discussion of remediated worlds of natural scenic beauty in China. Guy asks:

How is nature represented (in this piece, if at all)? Is there reference to a physical setting (in this song or piece)? If so, what is its role? Are the values expressed in this piece consistent with ecological wisdom? How do our metaphors of the land influence the way we treat it? In what ways have musical creativity itself affected humankind's relationship to the natural world? In what ways and to what effect is the environmental crisis seeping into contemporary musical production? (Guy 2009, p. 220)

Drawing the conversations around the examples I highlight above together to a close, I can only answer some of Guy's and Rees' questions in partiality. To begin with, Taiwanese contexts are different to Chinese ones with regards to understanding public duty to the environment in activist versus aestheticised ideals. That said, rising ground- and activist-led green movements have been emerging in China visà-vis anxieties over pollution in Beijing and food safety from a broader ecological point of view. ${ }^{4}$ However, as far as values expressed in mediated soundscapes are concerned, the ecological wisdom inherent in many sounded engagements with nature metaphorises political issues into acoustemologic practices. Sonic ways of engaging with the world - through the channelling of Chinese religion, cosmology, philosophy, 'civilised' behaviour, and the aesthetics of self-cultivation-ultimately reify broader state-determined approaches towards environmentalism. Many of these are inevitably constructed as national, and nationalist issues.

By the last statement, I refer to the specific, newer policies of Chinese head of state Xi Jinping, who has made environmentalism a new, centrally-controlled, topdown issue via a system of nationally-organised rewards and punishment (in the massive cutting down of domestic coal consumption for example, while problematically outsourcing these overseas). More crucially, 'nature' has been turned into a national asset, as seen in Xi's likening of China's 'green mountains [as] essentially gold mountains. ${ }^{5}$ In this light, the placing of megaphones in shrubbery and forests, proclaiming exhortative and edifying messages, or encouraging specific ways of aesthetically and sonically engaging with 'nature' (whether in co-performance of it or awed appreciation), can be viewed as phenomena which feed into the subsuming totality of state civilising projects.

One might argue here that such 'educational' projects-turning megaphones hidden in trees into default instruments of propaganda and advertising-may still

\footnotetext{
4 'Green Protests On The Rise in China.' Nature. By Natasha Gilbert, August 14, 2012. https://www. nature.com/news/green-protests-on-the-rise-in-china-1.11168, last accessed Dec 31, 2019.

5 'How Green is China?' New Internationalist, Nov 11, 2012. https://newint.org/features/2019/10/16/

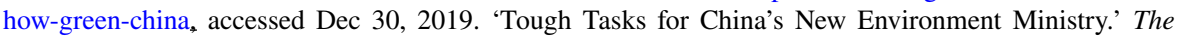
Diplomat, by Jackson Ewing, March 17, 2019.

https://thediplomat.com/2018/03/tough-tasks-for-chinas-new-environment-ministry/last accessed Dec 30, 2018.
} 
run parallel, simultaneous and mutually inclusive agenda on behalf of additional, individual agencies of separate and private Chinese citizens. After all, the slow and steady work conducted by these ubiquitous civic instructional signs and sonic mediations, in their rendering of nature as a consciously thought-about and 'everyday' phenomenon ingrained into individual people's awareness and lives, do require active in addition to reactive engagement. The question, then, lies in whether communities and individuals have also learnt to respond to these mediations in wider contexts of increased mass (social) media literacy, rapid economic growth and urbanisation, and the rise of a large middle class within China (with a corresponding explosion in domestic travel and tourism). Here, 'green' and environmental issues will be situationally and differently understood depending on differently-impacted precarities, human costs and opportunities presented to each listener on each occasion of sounding.

Thus, the young ballet dancer twirling in the $5{ }^{\circ} \mathrm{C}$ rain will hear the loudspeakers playing self-essentialising music in the natural environment of West Lake very differently from her audience of families young and old marvelling at the multimedia spectacle she is part of. Similarly, three very different religious devotees scaling different mountains thousands of kilometres apart, on concretised stairs so ubiquitous to the convenience and accessibility of mountain-climbing in China today, will have completely different experiences of and tolerance to electronically-amplified religious chants. A Daoist hermit looking for a spot of birdsong or silence in Shaanxi's Huashan will, for example, hear these mediations differently from a young woman praying for a child en route to making offerings at the Niang Niang temple in Gansu's Lianhuashan. In turn, a hard-of-hearing octogenarian pilgrim on both mountains who is surely grateful for the concrete stairs alongside the many pop-music blaring kiosks selling bottled water every $500 \mathrm{~m}$ along the hiking trail, will yet have a third different kind of appreciation for the sonic remediations. All across these experiences, generational divides will further bifurcate their sensitivities to certain kinds of sounded manifestations that accompany different generations of mobile phone technologies. But where does the human end and the non-human begin in this spectrum-making of organic orders in parsing 'nature' as a wider and total collection of diverse, living species on earth? I end this article through asking a final question: what would the rare giant panda-national symbol and treasure of China in its greatness and self-exoticism-want to listen to, then, in the interweaving mesh of acoustemological actioning of cosmological, human, political, and would-be environmental agenda? The answers will surely evolve as the age of the Anthropocene in China continues to do so, within and beyond its implications on sounded and ecological practices around the world.

Open Access This article is licensed under a Creative Commons Attribution 4.0 International License, which permits use, sharing, adaptation, distribution and reproduction in any medium or format, as long as you give appropriate credit to the original author(s) and the source, provide a link to the Creative Commons licence, and indicate if changes were made. The images or other third party material in this article are included in the article's Creative Commons licence, unless indicated otherwise in a credit line to the material. If material is not included in the article's Creative Commons licence and your intended use is not permitted by statutory regulation or exceeds the permitted use, you will need to obtain permission 
directly from the copyright holder. To view a copy of this licence, visit http://creativecommons.org/licen ses/by/4.0/.

\section{References}

Allen, Aaron S. 2011. Prospects and problems for ecomusicology in confronting a crisis of culture. Journal of the American Musicological Society 64 (2): 414-424.

Allen, Aaron S., and Kevin Dawe (eds.). 2015. Current directions in ecomusicology: Music, culture, nature. New York: Routledge.

Ames, Roger. 1984. The meaning of body in classical Chinese thought. International Philosophical Quarterly 24 (1): 39-54.

Brindley, Erica.F., 2012. Music, cosmology, and the politics of harmony in early China. New York: SUNY press.

Browning, Joseph. 2017. Mimesis stories: Composing new nature music for the shakuhachi. Ethnomusicology Forum 26 (2): 171-192.

Bull, Michael. 2001. The world according to sound: Investigating the world of Walkman users. New Media \& Society 3 (2): 179-197.

Chau, Adam Yuet. 2008. The sensorial production of the social. Ethnos 73 (4): 485-504.

Feld, Stephen. 2012. Sound and sentiment: Birds, weeping, poetics, and song in Kaluli expression, with a new introduction by the author. Durham NC: Duke University Press.

Guy, Nancy. 2009. Flowing down Taiwan's Tamsui river: towards an ecomusicology of the environmental imagination. Ethnomusicology 53 (2): 218-248.

Hubbert, Jennifer. 2010. Spectacular productions: Community and commodity in the Beijing Olympics. City \& Society 22 (1): 119-142.

Hubbert, Jennifer. 2013. Of menace and mimicry: The 2008 Beijing Olympics. Modern China 39 (4): 408-437.

Killick, Andrew. 2006. Holicipation: Prolegomenon to an ethnography of solitary music-making. Ethnomusicology Forum 15 (2): 273-299.

Kouwenhoven, Frank. 2006. Love songs and temple festivals in northwest China. IIAS Newsletter 40: 7.

Metzger, Sean. 2003. Ice queens, rice queens, and intercultural investments in Zhang Yimou's Turandot. Asian Theatre Journal 20 (2): 209-217.

Parks, Lisa. 2007. Around the antenna tree: the politics of infrastructural visibility. SIGGRAPH Art Gallery, p 345, https://digitalartarchive.siggraph.org/wp-content/uploads/2018/01/parks.pdf, Accessed 30 Dec 2019.

Rees, Helen. 2016. Environmental crisis, culture loss, and a new musical aesthetic: China's "Original Ecology Folksongs" in theory and practice. Ethnomusicology 60 (1): 53-88.

Shu-hua, Li. 2011. Construction of the Theoretical System in Plant Landscape Constructing Based on the Theory on Tian, Di, and Ren in the Practice of Landscape Architecture Construction. Chinese Landscape Architecture, 7.

Lam, Joseph. 1998. State sacrifices and music in Ming China: Orthodoxy, creativity, and expressiveness. New York: SUNY Press.

Magowan, Fiona, and Karl Neuenfeldt (eds.). 2005. Landscapes of Indigenous performance: Music, song and dance of the Torres Strait and Arnhem Land. Canberra: Aboriginal Studies Press.

Pedelty, Mark. 2011. Ecomusicology: Rock, folk, and the environment. Philadelphia: Temple University Press.

Picken, Laurence E., and Noël Nickson. 2007. Music from the Tang Court: Volume 7: Some ancient connections explored. Cambridge: Cambridge University Press.7

Puett, Michael. 2002. The ambivalence of creation: Debates concerning innovation and artifice in early China. California: Stanford University Press.

Schimmelpenninck, Antoinet. 1997. Chinese folk songs and folk singers: Shan'ge traditions in southern Jiangsu. Leiden: Chime Foundation.

Sterne, Jonathan. 2003. Sounds like the mall of America. In Music and Technoculture, ed. Rene T.A. Lysloff and Lesie C. Gay. Middletown: Wesleyan University Press. 
Tan, Shzr Ee. 2013. Beyond 'innocence': Amis aboriginal song in Taiwan as an ecosystem. London: Routledge.

Taylor, Tim D. 2012. The sounds of capitalism: Advertising, music, and the conquest of culture. Chicago: University of Chicago Press.

Weisgarber, Elliot. 2019. Shakuhachi, the voice of nature: A contemplative art and a source of Japanese musical tradition. Tokyo: John Weatherhill. 